\title{
Modelagem matemática da atividade de água em polpa cítrica peletizada
}

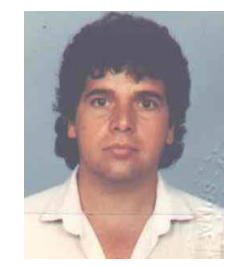

Paulo C. Corrêa ${ }^{1}$, Paulo C. Afonso Júnior ${ }^{2} \&$ Ednilton T. de Andrade ${ }^{3}$

1 DEA/UFV. CEP 36571-000, Viçosa, MG. Fone: (31) 3891-2270. E-mail: copace@mail.ufv.br (Foto)

2 DEA/UFV. E-mail: pjunior@alunos.ufv.br

${ }^{3}$ DEA/UFV. E-mail: etavares@alunos.ufv.br

Protocolo $145-29 / 11 / 2000$

\begin{abstract}
Resumo: Considerando-se a importância na formulação de rações mais elaboradas e de elevada qualidade nutricional para alimentação de animais objetivou-se, através deste trabalho, determinar as curvas de atividade de água para polpa cítrica peletizada, a qual foi submetida à dessorção e adsorção sob quatro condições de temperatura $\left(20,25,30\right.$ e $\left.35^{\circ} \mathrm{C}\right)$ e quatro umidades relativas do ar $(50,60,70$ e $80 \%)$ com três repetições, até a umidade de equilíbrio. A temperatura e a umidade relativa do ar (atividade de água) foram controladas por meio de uma unidade condicionadora de ar "Aminco-Aire". O modelo de Chen-Clayton com suas constantes determinadas para descrever as curvas de equilíbrio higroscópico da polpa cítrica peletizada, apresentou ajuste satisfatório aos dados experimentais, podendo ser utilizado para outras aplicações dentro dos limites deste experimento. Observou-se que nos tratamentos com temperatura acima de $30^{\circ} \mathrm{C}$ e atividade de água acima de 0,80, as amostras apresentaram desenvolvimento de fungos.
\end{abstract}

Palavras-chave: polpa cítrica peletizada, equilíbrio higroscópico, atividade de água

\section{Mathematical modeling of the water activity in peletized citrus pulp}

\begin{abstract}
Considering the importance of the citrus pulp in the formulation of elaborated rations and high nutritional quality for animal feed, this study had as its objective the determination of the water activity curves for peletized pulp citrus. The pulp was submitted to the desorption and adsorption under four conditions of temperature $\left(20,25,30\right.$ and $35^{\circ} \mathrm{C}$ ) and four relative humidity $(50,60,70$ and $80 \%)$ with three replications, until it reached the equilibrium moisture content. The temperature and the relative humidity of the air (water activity) were controlled by means of an air conditioning unit "Aminco-Aire". The model of Chen-Clayton (with determined constants to describe the curves of equilibrium moisture content of the peletized citrus pulp) presented a satisfactory adjustment to the experimental data and the same may be used for other applications within limits of this experiment. During the implementation of the experiment, it was observed that in the treatments above $30^{\circ} \mathrm{C}$ temperature and with water activity above 0.80 , the samples presented fungus development.
\end{abstract}

Key words: peletized citrus pulp, equilibrium moisture content, water activity

\section{INTRODUÇÃO}

A polpa cítrica peletizada é obtida por meio do tratamento de resíduos sólidos e líquidos remanescentes da extração do suco da laranja. Entre esses resíduos estão cascas, sementes e polpas, equivalendo a aproximadamente $50 \%$ do peso de cada fruta e apresentam teor de umidade em torno de $82 \%$ (van Soest, 1982). Depois de passar pelo processo de industrialização onde a polpa é triturada e seca até teores de umidade entre 11 e $12 \%$, o produto é peletizado, transformando um resíduo poluente em composto energético nobre a ser utilizado principalmente como complemento para a ração animal, devido à sua elevada digestibilidade e concentração de fibras (Deaville et al., 1994; Fegeros et al., 1995; Castro \& Zanetti, 1998; Oliveira et al., 1998).

Uma vantagem adicional à utilização da polpa cítrica na dieta animal, além de suas qualidades nutricionais, está relacionada à época de sua produção (maio a fevereiro) uma vez que compreende a entressafra de grãos e a escassez de pastagens, justamente no período de elevação dos preços das principais matérias-primas utilizadas na fabricação de rações, constituindo-se em uma opção de importância econômica na composição de custos para alimentação de animais.

É muito importante, para garantir a qualidade do composto alimentar, que a polpa cítrica seja transportada e armazenada em 
locais secos, ventilados e totalmente cobertos e, principalmente, com baixos teores de umidade pois, do contrário o desenvolvimento de microrganismos pode causar fermentações indesejáveis e contaminações por toxinas, que inviabilizam a utilização do produto na composição de rações para consumo animal. Dos microrganismos que colonizam os produtos agrícolas, os fungos são os mais tolerantes a baixas disponibilidades de água e são, conseqüentemente, importantes causas de deterioração (Sauer, 1992).

Como todo material higroscópico, a polpa cítrica tem a propriedade de ceder ou absorver água do ambiente tendendo, constantemente, a manter uma relação de equilíbrio entre o seu teor de umidade e a umidade do ar. Este equilíbrio, também denominado umidade de equilíbrio higroscópico, vem a ser o teor de umidade da polpa cítrica cuja tensão de vapor d'água é igual à do ar ambiente.

A presença da água no produto pode ser medida de diferentes formas, mas nem todos os métodos indicam a disponibilidade da água para os microrganismos, uma vez que nem toda a água do produto está igualmente disponível. A disponibilidade da água em materiais higroscópicos, tais como frutos e derivados, é melhor indicada pela atividade de água (Aw) ou pela umidade de equilíbrio com a umidade relativa do ar ambiente. A atividade de água e a umidade relativa, quando se estabelece o equilíbrio, são numericamente iguais (Hall, 1980; Brooker et al., 1992).

Christensen \& Kaufmann (1974) estudaram a influência da atividade de água, para diversos produtos de origem vegetal, no comportamento dos principais fungos sob condições ótimas de temperatura $\left(26\right.$ a $\left.30{ }^{\circ} \mathrm{C}\right)$ e verificaram que, em geral, atividades de água superiores a 0,70 são favoráveis à sobrevivência e desenvolvimento de fungos do gênero Aspergillus sp.; já, os fungos do gênero Penicillum sp. precisam de atividades de água maiores necessitando, em sua maioria, de valores superiores a 0,85 .

Inúmeros autores têm estudado o comportamento higroscópico de vários produtos agrícolas, utilizando métodos diferenciados para expressar a atividade de água em função da temperatura e do teor de umidade de equilíbrio (Brooker et al., 1992; Sun \& Woods, 1994; Morey et al., 1995; Chen \& Jayas, 1998; Corrêa et al, 1998). O estabelecimento de curvas de equilíbrio higroscópico é importante para definir limites de desidratação do produto, estimar as mudanças de umidade sob determinada condição de temperatura e umidade relativa e para definir os teores de umidade propícios ao início de atividade de agentes que irão provocar a deterioração do produto. Considerando-se a importância da polpa cítrica na formulação de rações mais elaboradas e de elevada qualidade nutricional para alimentação de animais, e que a indústria brasileira processa por ano aproximadamente 10 milhões de toneladas de laranja, o que representa uma produção média de 1.000 t de polpa cítrica desidratada (FAO, 1997) este trabalho teve, como objetivo, determinar as curvas de equilíbrio higroscópico para polpa cítrica peletizada.

\section{MATERIAL E MÉTODOS}

Este trabalho foi desenvolvido no Laboratório de Armazenamento e Processamento de Produtos Vegetais do
Departamento de Engenharia Agrícola da Universidade Federal de Viçosa, Viçosa, MG.

O delineamento experimental foi inteiramente casualizado com quatro níveis de temperatura $\left(20,25,30\right.$ e $\left.35^{\circ} \mathrm{C}\right)$ e quatro níveis de umidade relativa do ar de equilíbrio $(50,60,70$ e $80 \%)$ com três repetições, enquanto as condições ambientais para a realização dos testes foram obtidas utilizando-se uma unidade condicionadora de atmosfera de fabricação da empresa Aminco, modelo Aminco-Aire 150/300 CFM, dotada de dispositivos para o controle da temperatura e umidade relativa do ar fornecido e o equipamento era composto por bandejas removíveis com fundo telado, para permitir a passagem do ar por entre a massa de produto. O fluxo de ar foi monitorado com o auxílio de um anemômetro de hélice e mantido constante em torno de $10 \mathrm{~m}^{3} \mathrm{~min}^{-1} \mathrm{~m}^{-2}$; já a temperatura e a umidade relativa do ar foram monitoradas por meio de psicrômetro instalado próximo às bandejas contendo as amostras (Figura 1).

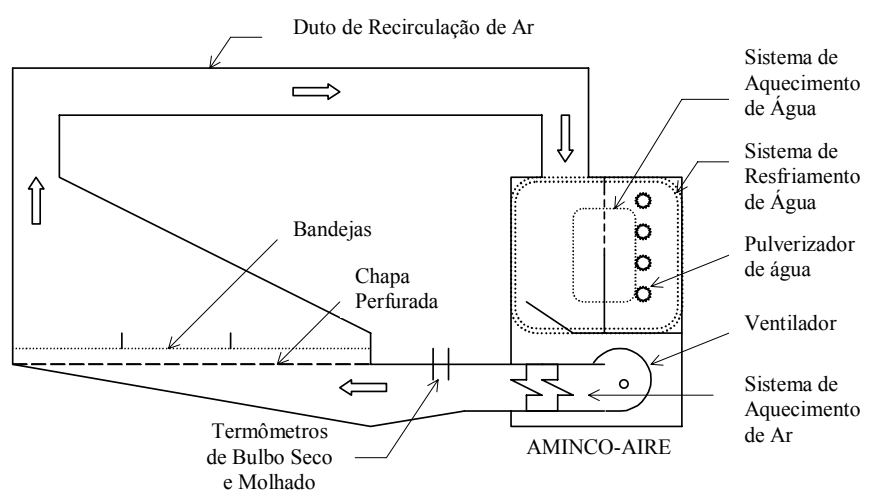

Figura 1. Desenho esquemático do equipamento experimental

As amostras foram, inicialmente, acondicionadas em sacos de polietileno e armazenadas em câmara fria, a temperatura de $4 \pm 1{ }^{\circ} \mathrm{C}$, sendo retiradas da câmara $12 \mathrm{~h}$ antes do início da operação permitindo, assim, o seu equilíbrio térmico com o ambiente. Para todos os testes utilizaram-se amostras de polpa cítrica peletizada de aproximadamente $350 \mathrm{~g}$ com teor de umidade inicial de $12,35 \%$ base seca (11\% base úmida) expostas ao fluxo de ar em camada fina para cada repetição de cada tratamento.

Durante o processo de dessorção e adsorção, as bandejas contendo as amostras foram pesadas, periodicamente, visando acompanhar a perda ou ganho de peso durante o processo; para tanto, considerou-se que o equilíbrio higroscópico havia sido alcançado quando a variação da massa das bandejas entre três pesagens fosse igual ou inferior a 0,001 g. Aos dados experimentais de equilíbrio higroscópico de polpa cítrica peletizada foram ajustados seis modelos matemáticos, com aplicação reconhecida na predição de atividade de água de produtos agrícolas (Tabela 1).

Para o ajuste dos modelos matemáticos aos dados experimentais de atividade de água, realizou-se análise de regressão não linear, pelo método Quasi-Newton, utilizando-se o programa computacional STATISTICA 5.0. Estimaram-se os valores dos parâmetros dos modelos em função das variáveis independentes temperatura do ar e umidade de equilíbrio do produto. 
Tabela 1. Modelos matemáticos empregados na predição da atividade de água de polpa cítrica peletizada

\begin{tabular}{|c|c|c|}
\hline Nome de Identificação & Modelo & \\
\hline Equação de Chen-Clayton & 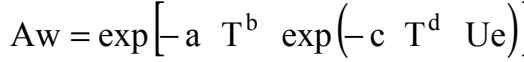 & (1) \\
\hline Equação de Chung-Pfost & $A w=\exp [-a /(T+b) \exp (-c U e)$ & (2) \\
\hline Equação de Oswin & $\mathrm{Aw}=1 /\left\{\left[((\mathrm{a}+\mathrm{b} \mathrm{T}) / \mathrm{Ue})^{\mathrm{c}}+1\right.\right.$ & (3) \\
\hline Equação de Halsey & $A w=\exp \left\{-\left[\exp (a+b \quad T) / U^{c}\right]\right.$ & (4) \\
\hline Equação de Henderson & $A w=1-\exp \left[-a(T+273) U e^{c}\right.$ & $(5)$ \\
\hline Equação de Henderson Modificada & $A w=1-\exp \left[-a(T+b) U^{c} e^{c}\right]$ & (6) \\
\hline
\end{tabular}

Os dados experimentais foram comparados com os valores estimados por cada modelo, pelo erro médio relativo $(\mathrm{P})$ e pelo erro médio estimado (SE) conforme descrito a seguir:

$$
\begin{gathered}
\mathrm{P}=\frac{100}{\mathrm{n}} \sum(|\mathrm{Y}-\hat{\mathrm{Y}}| / \mathrm{Y}) \\
\mathrm{SE}=\sqrt{\left(\sum(\mathrm{Y}-\hat{\mathrm{Y}})^{2} / \mathrm{GLR}\right)}
\end{gathered}
$$

em que

$$
\begin{array}{ll}
\mathrm{n} & \text { - número de observações } \\
\mathrm{Y} & \text { - valor observado experimentalmente } \\
\hat{\mathrm{Y}} & \text { - valor calculado pelo modelo } \\
\text { GLR } & \text { - graus de liberdade do modelo }
\end{array}
$$

O grau de ajuste dos modelos matemáticos aos dados experimentais, baseou-se na magnitude do coeficiente de determinação ajustado (variância explicada) na magnitude dos erros médio relativo e estimado, e na análise do comportamento da distribuição dos resíduos.

\section{RESULTADOS E DISCUSSÃO}

Na Tabela 2 são apresentados os dados médios (três repetições) do teor de umidade de equilíbrio da polpa cítrica peletizada, em porcentagem base seca, para as diferentes combinações de temperatura e atividade de água.

Tabela 2. Valores médios experimentais de três repetições do teor de umidade de equilíbrio da polpa cítrica peletizada (\% b.s.) para as diferentes combinações de temperatura e atividade de água

\begin{tabular}{crccc}
\hline Temperatura & \multicolumn{4}{c}{ Atividade de Água } \\
\cline { 2 - 5 }$\left({ }^{\circ} \mathrm{C}\right)$ & 0,50 & 0,60 & 0,70 & 0,80 \\
\hline 20 & 10,89 & 14,91 & 17,33 & 22,35 \\
25 & 10,26 & 14,12 & 16,76 & 21,52 \\
30 & 9,13 & 13,61 & 16,16 & 20,10 \\
35 & 8,90 & 12,02 & 15,53 & 18,62 \\
\hline
\end{tabular}

É muito importante, para um armazenamento seguro, que o nível de atividade de água no material fique abaixo dos estabelecidos para o desenvolvimento de fungos ou patógenos no produto. Durante a realização do experimento observou-se que a polpa cítrica peletizada, quando exposta a temperaturas de 30 e $35^{\circ} \mathrm{C}$ e atividades de água iguais ou superiores a 0,80 , apresentou contaminação por fungos. Portanto, para um armazenamento seguro e livre do desenvolvimento de fungos e, conseqüentemente, de suas toxinas, torna-se necessário que o produto seja armazenado em condições inferiores à temperatura de $30^{\circ} \mathrm{C}$ e umidade relativa de $80 \%$.

$\mathrm{Na}$ Tabela 3 tem-se o resumo dos modelos ajustados por meio de regressão não linear aos dados experimentais de equilíbrio higroscópico da polpa cítrica peletizada.

Observa-se que a equação com base no modelo de Chen-Clayton foi a que melhor se ajustou aos dados observados de equilíbrio higroscópico de polpa cítrica peletizada, com coeficiente de determinação ajustado de 0,9880 , erro médio relativo de $1,4457 \%$ e erro médio estimado de 0,0346 , apresentando melhor comportamento para representar a higroscopicidade do produto; entretanto, a análise dos dados da Tabela 3 indica que as equações de Chung-Pfost, Henderson Modificada e Henderson também se mostraram adequadas para fornecer estimativas satisfatórias da atividade de água da polpa cítrica.

Os resíduos, baseados na diferença entre os valores experimentais e calculados para cada modelo matemático analisado, são apresentados na Figura 2, na qual se verifica que a distribuição dos valores residuais para os modelos de Oswin \& Halsey apresentou comportamento tendencioso, indicando serem esses modelos menos indicados para descrição da relação de higroscopicidade da polpa cítrica peletizada e o ambiente que a envolve; no entanto, para os modelos de Chen-Clayton, Chung-Pfost, Henderson e Henderson Modificada, observa-se distribuição aleatória dos resíduos, sugerindo que estas equações representam, de forma satisfatória, os resultados obtidos e o fenômeno estudado.

A quantidade de água absorvida ou perdida por um produto é controlada pelas pressões de vapor da atmosfera circundante, assim como pela temperatura e outras características deste produto. Pela Figura 3, pode-se determinar as circunstâncias em que a polpa cítrica peletizada ganhará ou perderá umidade, quando armazenada entre as temperaturas de 20 a $35^{\circ} \mathrm{C}$ e atividades de água de 0,50 a 0,80; esta figura apresenta, ainda, as curvas de atividade de água para a polpa cítrica peletizada, obtidas através de regressão não linear, utilizando-se o modelo de Chen-Clayton, com seus respectivos coeficientes de determinação $\left(\mathrm{R}^{2}\right)$ e erros médios relativo $(\mathrm{P})$ e estimado (SE). Foram plotados, na mesma figura, os valores médios experimentais do teor de umidade de equilíbrio para a polpa cítrica peletizada, e nela se observa que o teor de umidade de equilíbrio higroscópico da polpa cítrica peletizada, a certa 
Tabela 3. Parâmetros das equações ajustadas para se calcular as isotermas de atividade de água da polpa cítrica peletizada (Aw) em função da temperatura do ar (T) e do teor de umidade de equilíbrio do produto (Ue)

\begin{tabular}{ccccccc}
\hline \multirow{2}{*}{ Parâmetros } & \multicolumn{7}{c}{ Modelos Matemáticos } \\
\cline { 2 - 7 } & $\begin{array}{c}\text { Chen- } \\
\text { Clayton }\end{array}$ & $\begin{array}{c}\text { Chung- } \\
\text { Pfost }\end{array}$ & Oswin & Halsey & Henderson & $\begin{array}{c}\text { Henderson- } \\
\text { Modificada }\end{array}$ \\
\hline $\mathrm{a}$ & $-2,4368$ & 97,3261 & 15,4285 & 3,0139 & $1,9738 \times 10^{-4}$ & $1,1171 \times 10^{-3}$ \\
$\mathrm{~b}$ & $-0,1318$ & 34,3180 & $-0,1520$ & $-0,0174$ & 1,0094 & 33,5795 \\
$\mathrm{c}$ & 0,0319 & 0,0744 & 1,5215 & 1,2012 & - & 0,9683 \\
$\mathrm{~d}$ & 0,2574 & - & - & - & - & - \\
$\mathrm{R}^{2}$ & 0,9880 & 0,9864 & 0,9699 & 0,9596 & 0,9515 & 0,9799 \\
$\mathrm{P}(\%)$ & 1,4457 & 1,6956 & 2,6363 & 3,0724 & 3,5705 & 2,0485 \\
$\mathrm{SE}$ & 0,0346 & 0,0368 & 0,0548 & 0,0636 & 0,0735 & 0,0479 \\
Distribuição do Resíduo & Aleatório & Aleatório & Tendencioso & Tendencioso & Aleatório & Aleatório \\
\hline
\end{tabular}
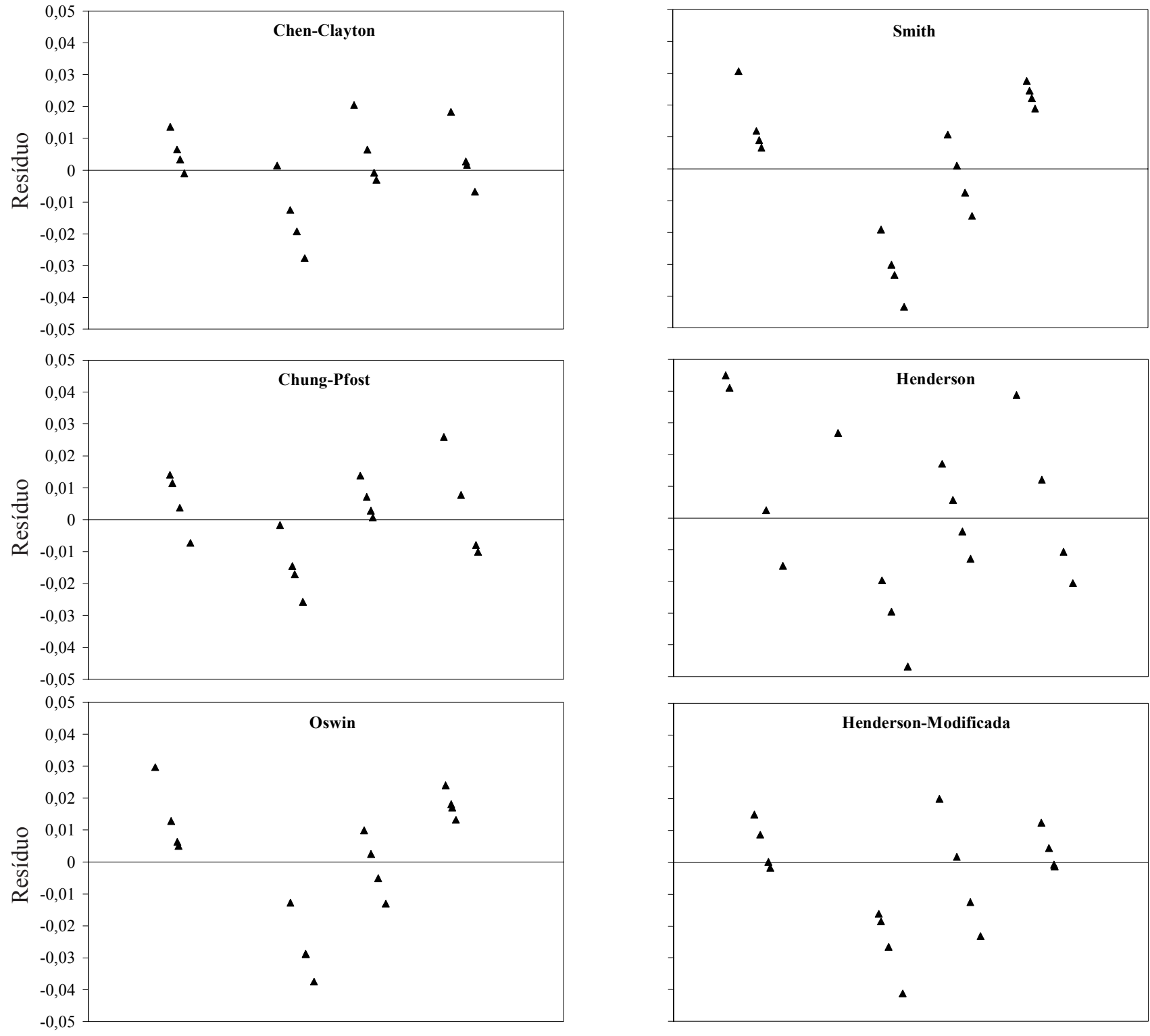

Valores Estimados

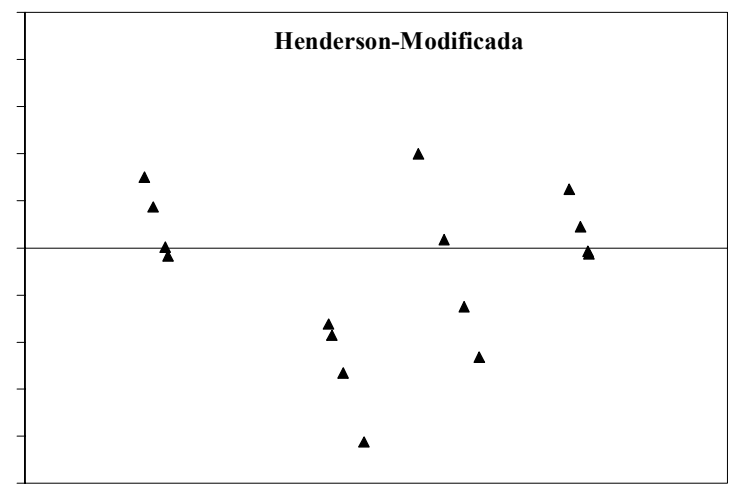

Valores Estimados

Figura 2. Distribuição dos resíduos para os modelos matemáticos analisados, em função dos valores estimados

atividade de água, é sempre menor para temperaturas mais elevadas. Ainda se constata, na Figura 3, que a equação de Chen-Clayton ajustada, atendeu aos requisitos ideais para descrever o equilíbrio higroscópico da polpa cítrica peletizada, apresentando boa precisão, generalidade, aplicabilidade em todas as faixas de umidade relativa e facilidade de uso podendo, assim, ser utilizada em outras aplicações envolvendo o teor de umidade de equilíbrio da polpa cítrica peletizada, dentro das faixas de temperatura e atividade de água estudadas neste trabalho. 


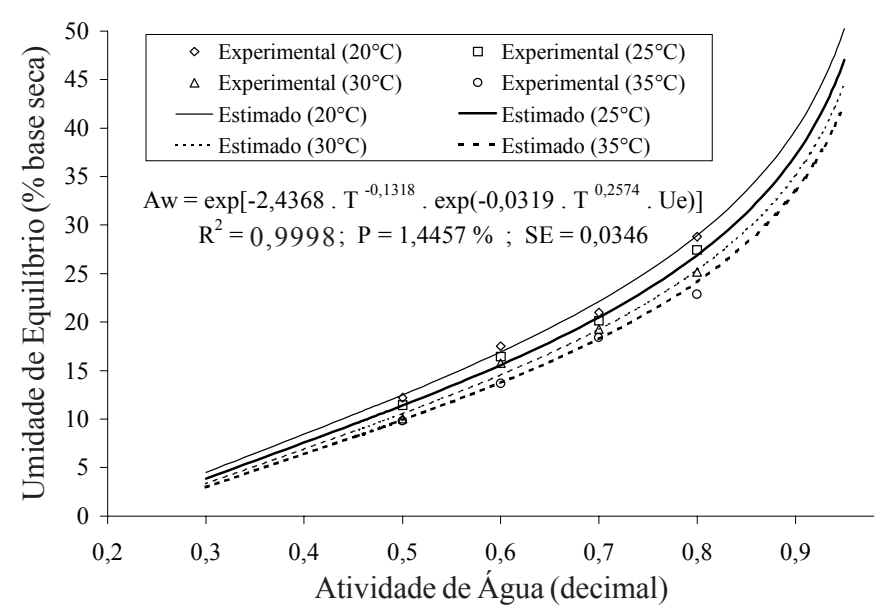

Figura 3. Curvas do teor de umidade de equilíbrio para polpa cítrica peletizada, obtidas por regressão não linear, utilizando-se o modelo de Chen-Clayton, com seus respectivos coeficientes de determinação $\left(\mathrm{R}^{2}\right)$ e erros médios relativo $(\mathrm{P})$ e estimado $(\mathrm{SE})$

A qualidade de produtos armazenados é dependente de seu valor de atividade de água, pois o teor da umidade do produto está diretamente associado a esta característica, e uma infecção, colonização e reprodução de fungos em produtos armazenados, são fortemente influenciados pela combinação dos fatores temperatura e atividade de água da massa de produto estocado, conforme estudos realizados por Christensen \& Kaufmann (1974).

\section{CONCLUSÕES}

Com base nos estudos realizados, conclui-se que:

1. A higroscopicidade da polpa cítrica peletizada apresentou características semelhantes desta propriedade física para a maioria dos produtos agrícolas já estudados, ou seja, o teor de umidade de equilíbrio diminui com o aumento de temperatura para uma mesma atividade de água mas aumenta com o aumento da atividade de água para uma mesma temperatura do ar.

2. O modelo matemático de Chen-Clayton com suas constantes determinadas para descrever as curvas de equilíbrio higroscópico da polpa cítrica peletizada, apresentou ajuste satisfatório aos dados experimentais, podendo ser utilizado para outras aplicações, dentro dos limites deste experimento.

3. Durante a realização do experimento observou-se que, nos tratamentos com a temperatura acima de $30{ }^{\circ} \mathrm{C}$ e atividade de água acima de 0,80 , as amostras apresentaram desenvolvimento de fungos.

\section{LITERATURA CITADA}

Brooker, D.B.; Bakker-Arkema, F.W.; Hall, C.W. Drying and storage of grains and oilseeds. Westport: The AVI Publishing Company, 1992. 450p.

Castro, A.K.; Zanetti, M.A. Estudo da inclusão de fibra na dieta de bezerros da raça holandesa. Revista Brasileira de Zootecnia, Viçosa, v.27, n.6, p.1193-1198, 1998.

Chen, C.; Jayas, D.S. Evaluation of the GAB equation for the isotherms of agricultural products. Transactions of ASAE, St. Joseph, v.41, n.6, p.1755-1760, 1998.

Christensen, C.M.; Kaufmann, H.H. Microflora. In: Christensen, C.M. Storage of cereal grain and their products. St. Paul: American Association of Cereal Chemists, 1974. p.158-192.

Corrêa, P.C.; Vital, R.B.; Martins, J.H. Higroscopicidade e entalpia de vaporização para madeira de Eucalyptus grandis. Revista Árvore, Viçosa, v.22, n.4, p.555-561, 1998.

Deaville, E.R.; Moss, A.R.; Givens, D.I. The nutritive value and chemical composition of energy-rich by-products for ruminants. Animal Feed Science Technology, New York, v.49, n.3-4, p.261-276, 1994.

FAO. Production Yearbook. Rome: Food and Agriculture Organization of the United Nations, v.51, 1997. 241p.

Fegeros, K.; Zervas, G.; Stamouli, S.; Apostolaki, E. Nutritive value of dried citrus pulp and its effect on milk yield and milk composition of lactating ewes. Journal Dairy Science, Savoy, v.78, n.5, p.1116-1121,1995.

Hall, C.W. Drying and storage of agricultural crops. Westport: The AVI Publishing Company, 1980. 381p.

Morey, V.; Wilcke, W.F.; Meronuck, R.A., Lang, J.P. Relationship between equilibrium relative humidity and deterioration of shelled corn. Transactions of ASAE, St. Joseph, v.38, n.4, p.1139-1145, 1995.

Oliveira, K.; Munhóz, F.C.; Curci, A.S.; Dalevedo, R.C.; Marques, D.; Hlavensky, E.V. Ração peletizada e farelada em diferentes proporções de consumo na alimentação de potros. Unimar Ciências, Maringá, v.7, n.2, p.89-93, 1998.

Sauer, D.B. Storage of cereal grains and their products. St Paul: American Association of Cereal Chemists, 1992. 615p.

Sun, D.W.; Woods, J.L. The selection of sorption isotherm equations for wheat based on the fitting of available data. Journal of Stored Products Research, London, v.30, n.1, p.27-43, 1994.

van Soest, T.J. Nutritional ecology of the ruminants. Corvallis, Oregon: OB Books Inc, 1982. 374p. 